\title{
Penyuluhan Kesehatan Hidup Sehat Bebas Plastik Di Jalan Melati, RT/RW 04/06, Kelurahan Binawidya, Tampan, Pekanbaru
}

\author{
Sri Hilma Siregar*, Wirdati Irma. Hasmalina Nasution, Prasetya, Jufrizal Syahri, \\ Rahmiwati Hilma, Fitra Perdana, Trisiwi Kusumaningrum, Yenni Yernita, Pratiwi \\ Gasril, Nurlailli Nasution, Olif Syahbella \\ MIPA dan Kesehatan, Universitas Muhammadiyah Riau \\ email: srihilma@umri.ac.id
}

\begin{abstract}
Fried food is a snack that is very popular with Indonesian people. Both from the upper class and the lower class, all of them really like this fried snack. Due to a large umber of enthusiasts with this fried food, there has been a proliferation of fried food sellers, both on the roadside, in stalls or fried food sellers around. People generally like fried foods that are tasty, crunchy and still hot. The use of plastic is not only added to food or drinks, but also the culture of using plastic as a plastic bag is still very high. Every human being always uses a plastic bag when they go shopping, be it at the people's market, stall, mall or supermarket. This further increases the amount of plastic waste. We know that this plastic is very difficult to decompose in the soil, if this happens continuously it will damage the soil ecosystem, causing environmental damage. This is what makes us educate the public about the side effects of using excessive plastic. In this service, we explain and invite the public to be wise in using plastic. In this service we also give free health checks, namely blood type and blood pressure.
\end{abstract}

Keywords: plastic, plastic waste, blood group

\begin{abstract}
Abstrak
Makanan gorengan merupakan makanan ringan yang sangat digemari oleh masyarakat Indonesia. Baik dari kalangan atas maupun kalangan kelas bawah, semuanya sangat menyukai makanan ringan gorengan ini. Dikarenakan banyaknya peminat dengan makanan gorengan ini, sehingga menjamurnya penjual gorengan, baik di pinggir jalan, di warungwarung ataupun yang pejual gorengan keliling. Masyarakat pada umumnya suka dengan gorengan yang gurih, renyah dan masih panas. Penggunaan plastik bukan hanya sekedar untuk ditambahkan dalam makanan atau minuman, tetapi juga budaya penggunaan plastik sebagai kantong plastik masih sangat tinggi. Setiap manusia selalu menggunakan kantong plastik ketika mereka pergi berbelanja baik itu ke pasar rakyat, warung, mall ataupun swalayan. Hal ini semakin menambah jumlah limbah plastik. Kita tahu bahwa plastik ini sangat susah terurai di tanah, jika hal ini terjadi terus menerus akan merusak ekosistem tanah sehingga menyebabkan kerusakan lingkungan. Hal inilah yang membuat kami untuk melakukan penyuluhan ke masyarakat mengenai efek samping dari penggunaan plastik yang berlebihan. Pada pengabdian ini kita menjelaskan dan mengajak masyarakat untuk bijak dalam penggunaan plastik. Pada pengabdian ini kita juga memberikan pemeriksaan kesehatan gratis yaitu golongan darah dan tensi.
\end{abstract}

Kata Kunci: plastik, limbah pelastik, golongan darah 


\section{PENDAHULUAN}

Permasalahan lingkungan yang telah menjadi isu global (mendunia), setelah hampir semua elemen masyarakat menyadari akan bahaya yang ditimbulkan dari kerusakan lingkungan. Salah satu penyebab kerusakan lingkungan adalah pencemaran lingkungan yang disebabkan oleh menumpuknya limbah yang dihasilkan oleh manusia. Bermacam limbah yang dihasilkan oleh aktivitas manusia setiap harinya, ada yang berujud padat, cair dan gas. Limbah yang berujud padat disebut dengan sampah. Beragam aktivitas manusia dapat menimbulkan sampah, baik aktivitas industri, pertanian, rumah sakit, maupun aktivitas domestik (rumah tangga) (Fauzi, 2019).

Ada banyak variasi bahan plastik yang dapat digunakan untuk keperluan rumah tangga hanya penggunaan sekali pakai. Hal ini dapat meningkatkan beban limbah plastik ke lingkungan. Penggunaan plastik seperti wadah minuman dan pembungkus makanan lebih sering dibuang sembarangan. Sampah wadah minuman dengan mudah dapat ditemukan dipinggir jalan, selokan, sungai-sungai, pantai dan laut. Ini menunjukkan bahwa pengelolaan sampah plastik sangat kurang ditanggani. Permasalahan tersebut muncul oleh karena masih rendahnya pengetahuan masyarakat tentang bahaya limbah plastik bagi lingkungan maupun manusia (Fauzi, 2019).

$2008 \begin{array}{cr}\text { Undang-undang Nomor } 18 \text { Tahun } \\ \text { tentang }\end{array}$

Sampah(selanjutnya disebut Undangundang Sampah) menggolongkan sampah terdiriatas (a) sampah rumah tangga; (b) sampah sejenis sampah rumah tangga; dan(c) sampah spesifik. Sampah rumah tangga berasal dari kegiatan sehari-hari dalam rumah tangga, tidak termasuk tinja dan sampah spesifik. Sampah spesifikmeliputi: (a) sampah yang mengandung bahan berbahaya dan beracun; (b)sampah yang mengandung limbah bahan berbahaya dan beracun; (c) sampahyang timbul akibat bencana; (d) puing bongkaran bangunan; (e) sampah yangsecara teknologi belum dapat diolah; dan/atau (f) sampah yang timbul secara tidakperiodik (Pasal 2 ayat (1) sampai dengan ayat (4) Undang-undang Sampah). Undang-undang sampah tidak mengatur pengelolaan sampah berdasarkan sifatnya yang mudah diurai atau tidak terurai, bahkan dalam Undang-undang sampah tersebut tidak ditemukan kata "sampah plastik (Dewi, 2019).

Jenis sampah yang paling potensial merusak lingkungan adalah jenis sampah anorganik, khususnya sampah plastik. Hal ini dikarenakan sampah jenisini tidak dapat mengalami pembusukan secara alami sebagaimana sampahorganik sehingga materi ini akan terus terkumpul selama beribu tahun di tanahtanpa adanya proses penguraian oleh bakteri dekomposer. Selain itu, hal ini juga disebabkan budaya masa kini yang serba instan dimana penggunaan materi berbahan plastik, dari sektor rumah tangga (konsumen) dan sektor industri (pelakuusaha), semakin meningkat yang pada akhirnya semakin banyak pula sampah plastik yang sulit terurai (Dewi, 2019).

\begin{tabular}{lrr}
\multicolumn{2}{c}{ Sampah plastik dapat } & bertahan \\
hingga bertahun-tahun & sehingga \\
menyebabkan pencemaran & terhadap \\
lingkungan. Sampah plastik tidaklah \\
bijakjika dibakar karena akan
\end{tabular} menghasilkan gas yang akan mencemari udara danmembahayakan pernafasan manusia, dan jika sampah plastik ditimbun dalamtanah maka akan mencemari tanah, air tanah. Plastik sendiri dikonsumsi sekitar100 juta ton/tahun di seluruh dunia (Dewi, 2019).

Kemungkinan lain yang akan terjadi adalah bahwa diprediksi akan terjadi penambahan jumlah sampah plastik di laut sehingga suatu saat nanti akan sangat banyak jumlahnya dan dapat mempengaruhi kehidupan biota air, apalagi status Indonesia sebagai Negara dengan garis pantai terpanjang setelah Kanada, akan menjadi ironi jika jumlah 
plastik di laut akan melebihi jumlah ikan.Kesadaran manusia akan bahaya sampah pastik tersebut perlu ditingkatkan agar pola hidup serta perilaku peduli lingkungan dapat menjadi awal pelestarian lingkungan yang lebih baik. Jika masyarakat semakin paham tentang bahaya sampah plastik maka akan terjadi penekanan terhadap jumlah produksi sampah plastik (Baunsele, 2020).

Tujuan kegiatan penyuluhan tentang hidup sehat tanpa plastik di kelurahan binawidya, tampan, pekanbaru adalah :

1. Meningkatkan kesadaran dan pemahaman masyarakat tentang bahaya plastik sehingga mereka mengetahui dampak apabila terlalu sering menggunakan plastik

2. Memberi informasi untuk mengurangi penggunaan plastik serta penanganan limbah plastik

\section{METODE PENGABDIAN}

Untuk meningkatkan wawasan masyarakat tentang bahaya limbah plastik, maka salah satu cara yang dapat dilakukan adalah dengan melakukan penyuluhan tentang bahaya limbah plastik. Dengan adanya penyuluhan ini, diharapkan dapat mengembangkan wawasan masyarakat agar lebih sadar akan bahaya limbah plastik. Harapan kedepannya para peserta yang mengikuti sosialisasi ini dapat melanjutkan kembali ilmu yang mereka dapatkan kepada orang lain.

\subsection{Sasaran dan Target Luaran}

Khalayak sasaran dalam kegiatan ini adalah masyarakat, terutama ibu rumah tangga. Kegiatan penyuluhan ini diharapkan menghasilkan suatu luaran sebagai berikut :

1. Peserta penyuluhan ini dapat mengerti dan paham tentang bahaya limbah plastik.

2. Meningkatkan pengetahuan peserta penyuluhan dan memberikan kesadaran tentang efek samping dari penggunaan plastik yang berlebihan.

3. Mengembangkan kepedulian masyarakat untuk hidup sehat.

\subsection{Materi}

Materi yang disampaikan dalam kegiatan pengabdian kepada masyarakat di kelurahan Binawidya, Tampan, Pekanbaru dengan tema "Hidup Sehat Tanpa Limbah Plastik" menyampaikan tentang bahaya limbah plastik, bagaimana pandangan kesehatan tentang sampah plastik yang disampaikan oleh tim penyuluh yang terdiri dari dosen-dosen Fakultas MIPA dan Kesehatan Universitas Muhammadiyah Riau kepada masyarakat kelurahan Binawidya, Tampan, Pekanbaru.

\subsection{Metode Yang Digunakan}

\section{Ceramah}

Materi yang diberikan adalah penjelasan tentang bahaya limbah plastik. Dalam metode ceramah didukung oleh visualisasi dari LCD dan microfon/pengeras suara.

\section{Diskusi}

Pada tiap materi yang disampaikan, peserta dapat bertanya kepada pemateri dan berdiskusi dengan tim pengabdian. Pada sesi tanya jawab, peserta diberikan kesempatan untuk bertanya kepada narasumber.

\section{Pemeriksaan kesehatan}

Peserta diberi kesempatan untuk melakukan pemeriksaan kesehatan oleh tim pengabdian, diantaranya cek tekanan darah (tensi) dan cek golongan darah. Dalam metode pemeriksaan kesehatan, dilakukan secara bergiliran.

Narasumber yang memberikan pelatihan terdiri dari 2 orang, dengan penanggung jawab bidang masing-masing dapat dilihat pada tabel 1. Berikut : 
Tabel 1. Narasumber Kegiatan

\begin{tabular}{|c|l|l|l|}
\hline $\begin{array}{c}\text { N } \\
\text { o }\end{array}$ & \multicolumn{1}{|c|}{$\begin{array}{c}\text { Kenis } \\
\text { Kegiatan }\end{array}$} & $\begin{array}{l}\text { Narasum } \\
\text { ber }\end{array}$ & $\begin{array}{l}\text { Penanggu } \\
\text { ng Jawab }\end{array}$ \\
\hline 1. & $\begin{array}{l}\text { Pemapara } \\
\text { n materi } \\
\text { mengenai } \\
\text { bahaya } \\
\text { plastik } \\
\text { dan } \\
\text { limbah } \\
\text { plastik }\end{array}$ & $\begin{array}{l}\text { Nurlaili, } \\
\text { M. Si }\end{array}$ & $\begin{array}{l}\text { Dr. Sri } \\
\text { Hilma } \\
\text { Siregar, } \\
\text { M.Sc }\end{array}$ \\
\hline 2. & $\begin{array}{l}\text { Pemeriksa } \\
\text { an }\end{array}$ & $\begin{array}{l}\text { Dr. } \\
\text { Wirdati }\end{array}$ & $\begin{array}{l}\text { Dr. Sri } \\
\text { Hilma } \\
\\
\end{array}$ \\
& Kesehatan & $\begin{array}{l}\text { Irma, M. } \\
\text { Siregar, } \\
\text { Si }\end{array}$ & M.Sc \\
\hline
\end{tabular}

\section{HASIL DAN PEMBAHASAN}

Kegiatan penyuluhan tentang bahaya plastik di kelurahan Binawidya, Tampan, Pekanbaru pada Oktober 2019, kegiatan penyuluhan ini ditujukan bagi masyarakat kelurahan Binawidya, Tampan, Pekanbaru dan kegiatan penyuluhan ini mendapat sambutan yang baik oleh masyarakat setempat. Kegiatan penyuluhan dilaksanakan di rumah ibuk Dr. Sri Hilma Siregar, M. Sc di jalan Melati, rt/rw 04/06, kelurahan Binawidya, Tampan, Pekanbaru. Acara ini dihadiri oleh 27 peserta yang terdiri dari $23 \mathrm{ibu}$ rumah tangga dan 4 pelajar/SD. Masyarakat yang datang pada acara ini ingin mengetahui dan menambah wawasan tentang bahaya pencemaran dari limbah plastik.

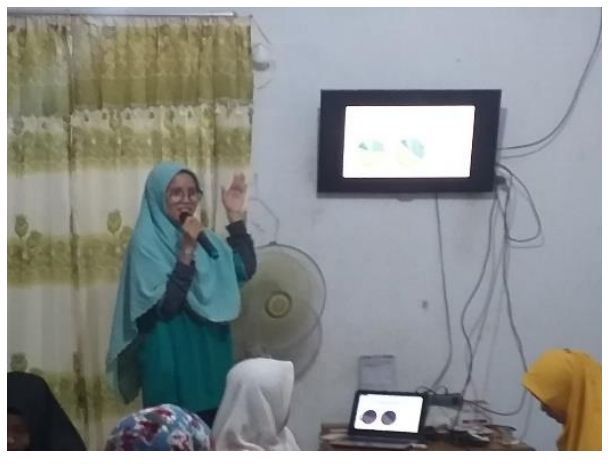

Gambar 1. Pemaparan Dampak Pencemaran Limbah Plastik
Hasil dari kegiatan pengabdian kepada masyarakat bagi masyarakat kelurahan Binawidya, Tampan, Pekanbaru antara lain

1. Kegiatan pengabdian masyarakat dilakukan dengan metode ceramah dan diskusi dengan peserta kegiatan yang dihadiri oleh 27 peserta yang terdiri dari 23 ibu rumah tangga dan 4 pelajar SD. Peserta yang datang pada acara ini ingin mengetahui dan menambah wawasan tentang bahaya pencemaran dari limbah plastik.

2. Secara keseluruhan kegiatan pelatihan yang dilakukan berjalan dengan lancar dan tertib. Pelatihan ini memberikan pengetahuan baru terhadap masyarakat tentang bahaya limbah plastik. Peserta antusias dalam mengikuti pelatihan yang terlihat pada saat kegiatan berlangsung di mana peserta pelatihan berperan aktif dalam sesi diskusi dan tanya jawab. 3. Kegiatan pengabdian kepada masyarakat dilakukan pada hari Minggu, 13 Oktober 2019. Dimulai dari registrasi peserta, sambutan sekaligus membuka acara kemudian masuk ke materi. Kegiatan selanjutnya diselingi dengan pemeriksaan kesehatan gratis, cek golongan darah dan cek tekanan darah (tensi). Output yang diharapkan setelah acara adalah peserta dapat mengerti dan paham tentang bahaya plastik dan lebih peduli terhadap lingkungan.

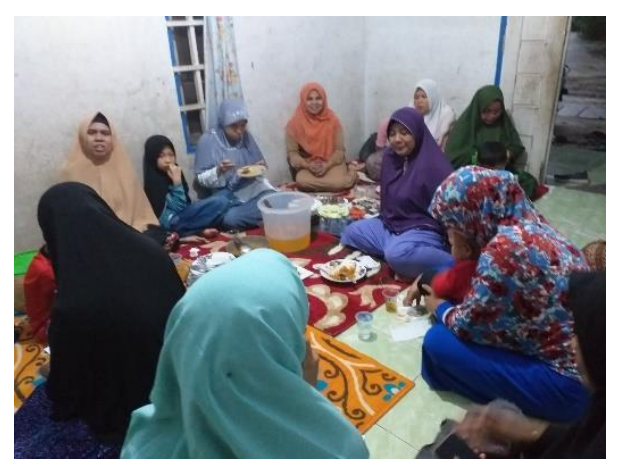

Gambar 2. Suasana Kegiatan Penyuluhan Bahaya Limbah Plastik 
Pemateri adalah Tim dosen Fakultas MIPA dan Kesehatan Universitas Muhammadiyah Riau. Kegiatan dimulai dengan ceramah tentang bahaya limbah plastik dan pentingnya kesadaran bagi masyarakat untuk selalu hidup sehat untuk mencegah dan mengurangi terjadinya akibat buruk yang dikarenakan penggunaan plastik yang terlalu berlebihan serta minim pengetahuan akan menanganinya. Dilanjutkan dengan sesi tanya jawab antara peserta dan pemateri. Melalui kegiatan pengabdian ini diharapkan menambah pengetahuan peserta tentang bahaya limbah plastik dan akibat yang timbul apabila terjadi perbuatan negatif tersebut. Hasil kegiatan secara garis besar mencakup beberapa komponen sebagai berikut: 1. Tujuan penyuluhan tercapai 3. Ketercapaian target materi yang telah direncanakan

4. Kemampuan peserta dalam penguasaan materi.

Secara keseluruhan kegiatan penyuluhan tentang bahaya limbah plastik ini dapat dikatakan berhasil. Keberhasilan ini selain diukur dari ketiga komponen di atas, juga dapat dilihat dari kepuasan peserta setelah mengikuti kegiatan.

\section{SIMPULAN}

Kegiatan penyuluhan tentang bahaya limbah plastik bagi masyarakat di kelurahan Binawidya, Tampan, Pekanbaru mendapat sambutan yang baik dari peserta dan berhasil dengan baik. Keadaan ini dapat dilihat dari kehadiran peserta yang memadai. Peserta terdiri dari masyarakat terutama ibu rumah tangga kelurahan Binawidya, Tampan, Pekanbaru.

Kegiatan Penyuluhan ini dapat diselenggarakan dengan baik dan berjalan dengan lancar sesuai dengan rencana kegiatan yang telah disusun. Kegiatan ini mendapat sambutan sangat baik terbukti dengan keaktifan peserta mengikuti penyuluhan dengan tidak meninggalkan tempat sebelum waktu penyuluhan berakhir.

\section{UCAPAN TERIMAKASIH}

Terima kasih disampaikan kepada Lembaga Penelitian dan Pengabdian Kepada Masyarakat Universitas Muhammadiyah Riau atas bantuan Pendanaan dari kegiatan ini.

\section{DAFTAR PUSTAKA}

[1] A. B. Baunsele, C. D. Q. M. Bulin, and H. Missa, "Upaya Peningkatan Pemahaman Terhadap Bahaya Sampah Plastik Dan Pengolahannya Bagi Siswa-Siswi SMA Negeri 3 Kota Kupang, Nusa Tenggara Timur," Patria, vol. 2, no. 1, p. 43, 2020

[2] M. Fauzi et al., "Pengenalan dan pemahaman bahaya pencemaran limbah plastik pada perairan di Kampung Sungai Kayu Ara Kabupaten Siak," Unri Conf. Ser. Community Engagem., vol. 1, pp. 341-346, 2019

[3] Y. Dewi and T. Raharjo, "Aspek Hukum Bahaya Plastik Terhadap Kesehatan dan Lingkungan Serta Solusinya," J. Chem. Inf. Model., vol. 53, no. 9, pp. 1689-1699, 2019.

[4] Moore, C. J., G. L. Lattin, and A. F. Zeller. 2004. Density of Plastic Particles Found in Zooplankton trawls from Coastal Waters of California to the North Pasific Central Gyre. Marina Drive, Long Beach CA 90803 (US): Algalita Marine Research Foundation.

[5] Mujiarto, I. 2005. Sifat dan karakteristik material plastik dan bahan aditif.Traksi, 3(2): 1-9. 